\title{
CARDIAC DISEASE IN PREGNANT WOMEN- AN EXPERIENCE IN A TERTIARY HOSPITAL IN KERALA
}

\author{
Deepa Mathews ${ }^{1}$, Asha Gopinath², Prasad Puthenpurayil Mani ${ }^{3}$
}

${ }_{1}^{1}$ Associate Professor, Department of Obstetrics and Gynaecology, Government Medical College, Kollam, Kerala, India. ${ }^{2}$ Associate Professor, Department of Obstetrics and Gynaecology, Government Medical College, Kottayam, Kerala, India. ${ }^{3}$ Cardiologist, General Hospital, Pala, Kerala, India.

\begin{tabular}{l}
\hline ABSTRACT \\
\hline BACKGROUND \\
Maternal cardiac disease contributes to a significant proportion of maternal mortality cases and severe maternal morbidity. The \\
proportion of cardiac disease such as Congenital Heart Disease (CHD) and Rheumatic Heart Disease (RHD) varies in different \\
countries. This is a descriptive study in which we retrospectively analysed all women with cardiac disease who delivered in \\
Government Medical College, Kottayam, from $01 / 01 / 2011$ to $31 / 12 / 2013$.
\end{tabular}

Aims and Objectives-

1. To study the proportion of different types of cardiac disease complicating pregnancy in parturients who delivered in Government Medical College and Hospital, Kottayam during the study period of three years.

2. To study the maternal and foetal outcome in parturients with cardiac disease during pregnancy, delivery and first postpartum week.

\section{MATERIALS AND METHODS}

It is a descriptive study and the data of women who met the inclusion criteria were collected from the hospital records using a proforma. The type of heart disease, cardiac complication developed during pregnancy, delivery and first post-partum week were recorded and analysed.

\section{RESULTS}

Out of 14,413 deliveries during study period, there were 181 women with cardiac disease (1.26\%). Out of the cardiac diseases, CHD were $60.22 \%$ and RHD were $36.46 \% ; 6.08 \%$ cases developed cardiac complications; $71.82 \%$ delivered vaginally and $27.62 \%$ underwent caesarean delivery; $91.16 \%$ foetuses were born term; $8.84 \%$ were born preterm; still birth was $1.66 \%$.

\section{CONCLUSION}

The proportion of women having cardiac disease were found comparable with that in other studies. RHD topped the list in other studies. But in our study, majority was CHD. There were no maternal deaths due to cardiac disease in the observed study period.

\section{KEY WORDS}

Cardiac Disease in Pregnancy, Congenital Heart Disease, Rheumatic Heart Disease.

HOW TO CITE THIS ARTICLE: Mathews D, Gopinath A, Mani PP. Cardiac disease in pregnant women- an experience in a tertiary hospital in Kerala. J. Evolution Med. Dent. Sci. 2018;7(23):2811-2813, DOI: 10.14260/jemds/2018/634

\section{BACKGROUND}

Pre-existing Cardiac Disease of mother in pregnancy may get worsened during pregnancy or labour and can affect maternal and neonatal outcome adversely. The women with congenital heart disease reaching adult age is increasing due to improvement in surgical management of these cases. The incidence of Rheumatic heart disease in developed countries has decreased very much. In those developed countries congenital heart disease, ischaemic heart disease and the like top the list. In underdeveloped countries Rheumatic heart disease still tops the list of maternal heart disease. The main objective of the present study was to find the proportion of the different cardiac lesions during pregnancy and to assess the effect of cardiac disease on maternal and foetal health.

'Financial or Other Competing Interest': None.

Submission 14-05-2018, Peer Review 26-05-2018,

Acceptance 28-05-2018, Published 04-06-2018.

Corresponding Author:

Dr. Asha Gopinath,

Department of Obstetrics and Gynaecology,

Government Medical College,

Kottayam, Kerala, India.

E-mail: drgnathasha@gmail.com

DOI: $10.14260 /$ jemds $/ 2018 / 634$

\section{(c) $\bigcirc(5)$}

\section{MATERIALS AND METHODS}

It is a descriptive study conducted at Government Medical College, Kottayam. We conducted a retrospective analysis of cardiac disease complicating pregnancy in women who delivered in Government Medical College, Kottayam, from 0101-2011 to 31-12-2013. The data of women who met inclusion criteria were collected using a proforma from the hospital records. The type of cardiac disease, period at which the cardiac disease was diagnosed, cardiac complication that developed during pregnancy, labour and first post-partum week were recorded. The details of delivery, baby weight and early neonatal outcome were assessed.

All women with cardiac disease who delivered a foetus weighing $\geq 500 \mathrm{gm}$ during the three years period from $01 / 01 / 2011$ to $31 / 12 / 2013$ were included in the study. Women with cardiac disease who underwent Medical Termination of Pregnancy or spontaneous abortion were excluded from the study.

\section{RESULTS}

There were 14,413 deliveries during the study period. The total number of cardiac disease complicating pregnancy during this period was $181(1.26 \%)$. Out of these cardiac diseases, 110 cases were CHD (60.22\%) and RHD comprising 
of 65 cases (36.46\%), miscellaneous cases were 6 (3.31\%) [Table 1].

Majority of the women belonged to age group 25 - 30 years $(44.2 \%) ; 50.28 \%$ women were nullipara [Table 2]; 48 out of 181 women had their cardiac disease detected in either present or past pregnancy. The commonest comorbidity was gestational hypertension [Table 3].

Out of 181 cardiac cases 130 women had vaginal delivery (71.82\%). Caesarean delivery was in 50 women $(27.62 \%)$. There was a laparotomy for ruptured uterus too; $91.16 \%$ of babies were born term and $8.84 \%$ preterm. Out of three still births, one was due to ruptured uterus. Two were in women who had Mitral Valve Replacement (MVR) and on anticoagulants. Among these, one woman underwent MVR during present pregnancy. The other woman was a defaulter who was not on follow-up [Table 4].

Atrial Septal Defect (ASD) was the most common congenital heart disease. Complex congenital heart disease was less in number. Maternal and foetal outcome in congenital heart disease group was better. RHD was the second common lesion. Almost all RHD included mitral valve disease [Table 5].

The cardiac complications recorded were cardiac failure, arrhythmia requiring pharmacotherapy, infective endocarditis and cardiac intervention in pregnancy. There were two cases of cardiac intervention [Table 6 and 7]. One was a case of balloon mitral valvotomy (BMV). In the second case closed mitral valvotomy (CMV) was attempted, but MVR had to be done. This patient had a pre-term still birth. There was no maternal death in the study population.

\begin{tabular}{|c|c|c|}
\hline & No. & $\%$ \\
\hline Total deliveries & 14413 & \\
\hline Cardiac diseases & 181 & 1.26 \\
\hline Congenital heart disease & 110 & 60.22 \\
\hline Rheumatic heart disease & 65 & 36.46 \\
\hline Miscellaneous & 6 & 3.31 \\
\hline \multicolumn{3}{|c|}{ Table 1. Details of Cardiac Cases } \\
\hline
\end{tabular}

\begin{tabular}{|c|c|c|}
\hline Age (Years) & No. & $\mathbf{\%}$ \\
\hline$<20$ & 4 & 2.21 \\
\hline $20-24$ & 62 & 34.25 \\
\hline $25-30$ & 80 & 44.20 \\
\hline $31-34$ & 23 & 12.71 \\
\hline$\geq 35$ & 12 & 6.63 \\
\hline Parity & 91 & 50.28 \\
\hline Nullipara & 80 & 44.20 \\
\hline Primipara & 10 & \\
\hline Multipara & Table 2. Details of Parturients \\
\hline \multicolumn{2}{|l}{} \\
\hline
\end{tabular}

\begin{tabular}{|c|c|c|}
\hline & No. & $\%$ \\
\hline Gestational hypertension & 19 & 17.27 \\
\hline Anaemia & 6 & 5.45 \\
\hline Diabetes & 3 & 2.73 \\
\hline Thyroid & 3 & 2.73 \\
\hline Hypertension + Diabetes & 1 & 0.9 \\
\hline $\begin{array}{c}\text { Hypertension + urinary tract } \\
\text { infection }\end{array}$ & 1 & 0.9 \\
\hline Seizure disorder & 1 & 0.9 \\
\hline \multicolumn{3}{|c|}{ Table 3. Details of Comorbidity } \\
\hline
\end{tabular}

\begin{tabular}{|c|c|c|}
\hline & No. & \% \\
\hline Vaginal delivery & 130 & 71.82 \\
\hline Caesarean delivery & 50 & 27.62 \\
\hline Laparotomy & 1 & 0.55 \\
\hline Term & 165 & 91.16 \\
\hline Preterm & 16 & 8.84 \\
\hline AGA & 121 & 66.85 \\
\hline SGA & 57 & 31.49 \\
\hline Stillborn & 3 & 1.66 \\
\hline \multicolumn{2}{|c|}{ Table 4. Obstetric and Neonatal Outcome } \\
\hline
\end{tabular}

AGA: Adequate for gestational age; SGA: Small for gestational age

\begin{tabular}{|c|c|c|c|}
\hline & No. & $\%$ & $\begin{array}{c}\text { Prior } \\
\text { Interventions } \\
\end{array}$ \\
\hline Congenital Heart Disease & 110 & & \\
\hline ASD & 47 & 42.73 & 26 \\
\hline VSD & 8 & 7.27 & 3 \\
\hline PFO & 3 & 2.73 & \\
\hline MVP & 5 & 4.55 & \\
\hline$M V P+M R$ & 19 & 17.27 & \\
\hline ASD + MVP +MR & 1 & 0.90 & \\
\hline $\mathrm{TR}+\mathrm{PAF}$ & 1 & 0.9 & \\
\hline PS & 1 & .9 & \\
\hline Complete heart block & 1 & 0.9 & \\
\hline PS + Complete heart block & 1 & 0.9 & \\
\hline MR + ASD closure & 1 & 0.9 & 1 \\
\hline $\mathrm{AS}$ & 3 & 2.73 & \\
\hline Bicuspid Aortic Value & 2 & 1.82 & \\
\hline TOF & 1 & 0.90 & \\
\hline Corrected TOF & 2 & 1.82 & 2 \\
\hline PDA + ASD & 1 & 0.9 & \\
\hline $\begin{array}{l}\text { Dextrocardia, situs } \\
\text { inversus }\end{array}$ & 1 & 0.90 & \\
\hline PDA & 4 & 3.64 & 2 \\
\hline Ebstein's Anomaly & 2 & 1.82 & \\
\hline $\mathrm{PDA}+\mathrm{AR}$ & 2 & 1.82 & \\
\hline Corrected TGA & 1 & 0.9 & 1 \\
\hline ASD + VSD & 3 & 2.73 & \\
\hline $\begin{array}{c}\text { Rheumatic Heart } \\
\text { Disease }\end{array}$ & 65 & & 14 \\
\hline MS & 5 & 7.69 & \\
\hline $\mathrm{MS}+\mathrm{MR}$ & 20 & 30.77 & \\
\hline MVP & 1 & 1.54 & \\
\hline MVP + MR & 6 & 9.23 & \\
\hline $\mathrm{MS}+\mathrm{MR}+\mathrm{AR}$ & 3 & 4.62 & \\
\hline $\mathrm{MS}+\mathrm{AR}$ & 2 & 3.08 & \\
\hline $\mathrm{MS}+\mathrm{AR}+\mathrm{ASD}$ & 1 & 1.54 & \\
\hline $\mathrm{MS}+\mathrm{MR}+\mathrm{TR}+\mathrm{PAH}$ & 1 & 1.54 & \\
\hline AR & 2 & 3.08 & \\
\hline Miscellaneous & 6 & & \\
\hline MR & 1 & & \\
\hline Arrhythmias & 3 & & \\
\hline Cardiomyopathy & 2 & & \\
\hline \multicolumn{4}{|c|}{ Table 5. Details of Cardiac Lesions } \\
\hline
\end{tabular}

ASD: Atrial Septal Defect, VSD: Ventricular Septal Defect, PFO: Patent Foramen Ovale, MVP: Mitral Valve Prolapse, MR: Mitral Regurgitation, TR: Tricuspid Regurgitation, PAH: Pulmonary Artery Hypertension, PS: Pulmonary Stenosis, AS: Aortic Stenosis, TOF: Tetralogy of Fallot, PDA: Patent Ductus Arteriosus, AR: Aortic Regurgitation, TGA: Transposition of Great Arteries. 


\begin{tabular}{|c|c|}
\hline NYHA Grade & No. \\
\hline Grade I & 119 \\
\hline Grade II & 46 \\
\hline Grade III & 10 \\
\hline Grade IV & 1 \\
\hline Table 6. Distribution as per Functional Grading \\
\hline
\end{tabular}

\begin{tabular}{|c|c|c|}
\hline Complication & No. & \% \\
\hline Cardiac failure in pregnancy & 5 & 2.76 \\
\hline Cardiac failure at caesarean & 1 & 0.55 \\
\hline Cardiac failure postpartum & 1 & 0.55 \\
\hline Arrhythmia requiring treatment & 1 & 0.55 \\
\hline Infective endocarditis & 1 & 0.55 \\
\hline Cardiac intervention in pregnancy & 2 & 1.10 \\
\hline Table 7. Cardiac Complication in Pregnancy \\
\hline
\end{tabular}

\section{DISCUSSION}

Our study provides a contemporary assessment of maternal and neonatal risk associated with pregnancy in women with cardiac disease who are receiving comprehensive prenatal care. The proportion of women with cardiac disease in our study was $1.26 \%$. The prevalence of cardiac disease in a review by $\mathrm{K}$. Pushpalata is $4 \%{ }^{1}$ The incidence of cardiac disease in women admitted for confinement was $1.3 \%$ in a rural tertiary care hospital in Maharashtra. ${ }^{2}$ This is comparable with our study.

The proportion of congenital heart disease in our study is $60.22 \%$ and RHD is $36.46 \%$. The proportion of congenital heart disease is $19.1 \%$ and RHD is $55.7 \%$ in a Brazilian study held from 1989 to 1999.3 The proportion of RHD is 77\% in the study from Maharashtra. ${ }^{2}$ In the study by Konar Hiralal in 2012 also, RHD was the most common cardiac disease complicating pregnancy amounting to $69.4 \%{ }^{4}$ But in a Canadian study, the most common cardiac disease in pregnancy is CHD (74\%). ${ }^{5}$ This is similar to our study. In the publication by Cleveland Clinic on pregnancy and heart disease in 2014, the cardiovascular disease complicates 1-4\% of pregnancies and congenital heart disease is the most common pre-existing condition. ${ }^{6}$

Our study had taken only women who delivered a foetus weighing $\geq 500 \mathrm{~g}$. Late post-partum events were not included in the study. The Confidential Review of Maternal Deaths (CRMD), Kerala revealed a mortality of $6.8 \%$ of total maternal deaths due to cardiac disease in the period 2004 - 2006. Among these, RHD topped the list. 7

In our study, the CHD was $60.22 \%$. In this group, ASD was $42.73 \%$. More than $50 \%$ of women with ASD had undergone corrective procedure before pregnancy. All the congenital CHD patients had good obstetric outcome. Complex congenital heart disease were rare. In our study, 48 women (26.52\%) were detected to have cardiac disease during present or previous pregnancy. This stresses the important good antenatal care in reducing the morbidity and mortality associated with cardiac disease in pregnancy.

Majority of the caesarean deliveries were for obstetric reasons, commonest being a previous caesarean. Out of the preterm babies, 2 were iatrogenic preterm. One baby was delivered at 24 weeks of gestation for elective ventilation of mother- case of severe mitral stenosis. Second preterm was following a caesarean for ventilation of the mother in dilated cardiomyopathy. Out of the stillbirths, one was due to ruptured uterus. Another stillborn was that of a mother who had undergone MVR and had been on anticoagulants and irregular follow-up presented late in pregnancy. This shows that prompt detection and good antenatal care improves the maternal and foetal outcome. Babies of 2 mothers with RHD had septal defects. Foetus of a mother with MVR who was on warfarin had small limbs.

Majority of the women with cardiac disease had uneventful course in pregnancy and labour. Cardiac failure is a dreaded complication in pregnancy. In our study $2.76 \%$ women had cardiac failure, but all were managed successfully. In another Indian study, cardiac failure was $7.4 \%{ }^{4}$ In our study population adverse cardiac events were with RHD and all were having severe disease. All the women in our study were seen in antenatal clinic and none presented for the first time in labour. This could be the reason for less complications when compared to a previous study in which few women had presented for the first time in labour. ${ }^{4}$

\section{CONCLUSION}

Cardiac disease complicating pregnancy is a high-risk situation and demands special attention throughout pregnancy and labour. Even though in developing countries, RHD is the most common lesion, 2,3,4 our study had more CHD than RHD. The number of women with CHD becoming pregnant is increasing. So, obstetricians should be aware of complications and need for special care in these women. In our study, outcome of mothers was good. No maternal mortality was there. All women with cardiac failure were promptly diagnosed and managed. But women with Eisenmenger's syndrome, severe cardiomyopathy and pulmonary vascular disease may not tolerate pregnancy and there may be grave consequences. Proper evaluation of maternal prognosis prior to conception and adequate clinical follow-up during pregnancy are both fundamental measures for obtaining a satisfactory outcome in these patients. In Kerala, the maternal mortality due to direct obstetric causes is declining. But morbidity and mortality due to heart disease may increase due to more congenital heart disease undergoing correction, and pregnancy before adulthood. Hence, it is necessary that high-risk obstetric units are ready for that.

\section{REFERENCES}

[1] Pushpalatha K. Cardiac diseases in pregnancy-a review. JIMSA 2010;23(4):269-74.

[2] Bangal VB, Singh RK, Shinde KK. Clinical study of heart disease complicating pregnancy. IOSR Journal of Pharmacy 2012;2(4):25-8.

[3] Avila WS, Rossi EG, Ramires JA, et al. Pregnancy in patients with heart disease: experience with 1,000 cases. Clin Cardiol 2003;26(3):135-42.

[4] Hiralal K, Chaudhuri S. Pregnancy complicated by maternal heart disease: a review of 281 women. J Obstet Gynaecol India 2012;62(3);301-6.

[5] Siu SC, Sermer M, Colman JM, et al. Prospective multicenter study of pregnancy outcomes in women with heart disease. Circulation 2001;104(5):515-21.

[6] Naderi S, Raymond R. Pregnancy and heart disease. Cleveland clinic proceedings. Published: February 2014.

[7] Paily VP, Ambujam K, Thomas B. Why mothers die. Report of confidential review of maternal deaths, Kerala 2006-2009. Kerala Federation of Obstetrics \& Gynaecology 2012. 